\title{
Effects of Forest Experience on Young Children's Playfulness and Emotional Intelligence
}

\author{
Yeon-Hee Lee* and Jin Jang \\ Department of Forest Welfare, National Institute of Forest Science, Seoul 02455, South Korea
}

\begin{abstract}
This study was conducted to investigate the effects of forest experience activities on the playfulness and emotional intelligence of children who participated in experience-based forest education programs. For this, pre and postquestionnaires were conducted with 53 children from ages three to five who attended forest experience programs from ‘Sonamu Nuri Forest Experience Center for Children' in Gangneung from March to November 2016. For the children to understand and answer the questions easily, teachers helped them to understand the questions about forest experience activities before they participated in the programs, and the nursing and head teachers who had been in charge of the children over 6 months assessed their behavioral changes with the pre and post questionnaires. The programs consist of observation and exploration activities, free plays, crafting with natural objects, five-sense activities, physical activities, etc. As a result, the children's playfulness and emotional intelligence showed statistically significant increase after the programs. Through the forest experience activities, the children could differentiate their own and others' emotions by accessing natural ecosystem and interacting with nature. Ultimately, the activities helped the participants improve the emotional intelligence to take the initiative and playfulness to cooperate with friends and play a leading role. The results of the investigation have a significance in enhancing the value of forest experience activities for children as well as providing basic data for expanding forest education for children and improving the quality. However, as this research was conducted with only 53 children, it can be difficult to generalize the results. Continuous observation of the variables and further discussion are also required, since the results were obtained from a single post-test. Therefore, follow-up research needs to investigate the relationship among variables more closely and perform continuous monitoring and effect verification.
\end{abstract}

Keywords: emotion, forest education, forest experience centre for little children, playing activity, preschooler

\section{Introduction}

The most important task in early childhood education is not knowledge education but seeking emotional and social development necessary for young children to grow up into members of a healthy society and ultimately live a happy life. In particular, early childhood is a very important period in the entire human life cycle in which $80-90 \%$ of one's personality is formed (Choi, 2013). At the beginning of early childhood, cognitive and linguistic abilities rapidly develop, as well as morality and personality traits. Moreover, children build peer relations and develop psychological stability and self-esteem, forming a positive self-concept, while also obtaining social skills necessary for them to grow into sound

Received: February 6, 2018, Revised: June 13, 2018, Accepted: June 14, 2018

First author: Yeon-Hee Lee, E-mail: shinerlee@korea.kr, ORCID: 0000-0002-6583-1396

*Corresponding author: Yeon-Hee Lee, E-mail: shinerlee@korea.kr, ORCID: 0000-0002-6583-1396 
members of the society. If problems occur in this period, there will be trouble in achieving developmental tasks later, thereby exerting a negative impact on personality development and social adjustment in childhood/adolescence and adulthood (K.H. Kim, 2016). Therefore, the environment where children are exposed to different experiences in early childhood can be considered a critical factor for their holistic growth.

Recently there has been a social consensus about the educational value and need for eco-friendly education. Thus, early childhood education is paying more and more attention to eco-friendly education, experience of nature and eco-early childhood education (Lee, 2011). Eco-friendly education is integrated education based on personality education that nurtures the attitude and ability to practice coexistent life by perceiving the value of nature and understanding the relations among humans, nature and natural objects through the educational approach that makes interaction and experience of nature as a daily routine. This provides young children with opportunities to experience nature as a physical environment, thereby giving them a chance to experience and understand physical natural objects, be familiar with the essentiality of 'nature' and concepts such as purity maternal instinct, spontaneity and freedom, and form imagery of them (Cho, 2005).

The forest is the best environment for eco-friendly education. Embracing all kinds of living things, the forest is an authentic and living place of education that helps children understand the dignity and value of life, have the attitude to respect diversity, and establish positive and creative thinking and healthy value system about coexistence between nature and humans. The forest makes young children to realize the order of nature, and provides them with entertainment that stimulates endless imagination and creativity. In fact, young children actually select surrounding environments and natural objects at the forest according to their own needs and play with them freely, through which they naturally make up things to play with and add significance to tools or natural objects necessary for their play, while also resolving various conflicts or issues that arise while they play (Kim, 2010; Hong, 2015).

Early childhood is the time when children establish the values to respect and love the living things and an extremely important period in forming an eco-friendly attitude (Baek, 2014). Therefore, early childhood is the most suitable period for forest experience activities as well as the right time to maximize the effects (Oh, 2017). Meanwhile, Richard (2005) finds the cause of young children's physical and mental health problems in nature deficit disorder. By claiming that young children experiencing nature deficit disorder may suffer physical and mental stress as well as psychological disorder, he finds the answer to young children's mental health and adjustment issues that are emerging as social problems in 'nature'.

In this background, early childhood education applying forest experience is promoted all over the country, and Korea Forest Service first began to create forest experience centers for young children in 2014 according to the Forest Education Promotion Act (2012) and has now increased them to 146 centers all over Korea as of 2017. A forest visitor center for little children is a facility to guide and educate young children so that they can experience various functions of forests, cultivate positive emotions and make holistic growth. It is more focused on nature experiences than artificial facilities. Forest guide for little children is allocated to forest visitor centers for little children, and such forest guide is one of the forest education specialists nurtured by Korea Forest Service who guides young children through forest experience activities based on knowledge and understanding about forests and young children.

Positive effects of forest experience activities on young children have been constantly reported by research. The following shows the result of examining the effects in terms of physical, emotional and cognitive aspects. First, regarding the physical aspect, a forest serves as a good place for play and exercise for young children, and forest experience activities enable young children to be engaged in more natural play and motions, thereby promoting healthy physical development and increasing physical activity (Choi, 2013; Kang, 2013). In addition, the activities also improve muscular strength as well as motor abilities such as endurance, flexibility and agility (S.M. Kim, 2016). Second, regarding the emotional aspect, forest experience activities have positive effects on young children's happiness and self-esteem, as well 
as social development and emotional expression (Kim, 2008; Jin, 2013; Yoo, 2013; Kim, 2014). Moreover, young children's stress and aggression are reduced by forest experience (Yun, 2013; Park, 2015). Lastly, forest experience activities promote young children's respect for life and eco-friendly attitude (An, 2006; Oh, 2014; Oh, 2017), while also showing positive effects on their cognitive development such as scientific investigation, scholastic ability and linguistic ability (Seo, 2007; Kim, 2013; Yoo, 2015; Son, 2016; Song, 2017).

Based on the above, the objective of this study is to determine the effects of forest experience activities on young children's playfulness and emotional intelligence, targeting young children that participated in forest experience-based education programs at a forest visitor center for little children organized and run by Korea Forest Service. The results of this study will prove how forest experience activities contribute to holistic development of young children, enhance the value of forest experience activities in early childhood education, and provide baseline data for expansion and qualitative improvement of forest education for young children.

The following research questions are established according to the objective of this study.

1) How do forest experience activities affect change in young children's playfulness?

2) How do forest experience activities affect change in young children's emotional intelligence?

\section{Methods}

\section{Subjects}

A forest visitor center for little children is defined as a facility for guiding and teaching little children by providing them with opportunities to experience various functions of forests so that they can cultivate emotions and grow up to be well-rounded persons, according to Article 12 of the Forest Education Promotion Act. The subjects of this study are 53 young children that participated in a forest experience programs at Sonamu Nuri Forest Visitor Center for Little Children in Gangneung, Korea.

\section{Procedures}

This study conducted a pretest-posttest survey on young children aged 3-5 that participated in forest experience programs regularly held for 2 hours every week at Sonamu Nuri Forest Visitor Center for Little Children located in Gangneung from March 22 to November 22, 2016. Total 57 copies of the questionnaire were collected, and 53 of them were used to analyze the research data excluding 4 copies with partial omissions, same responses and other unfaithful answers.

The survey was conducted by distributing the questionnaires to the daycare teachers at the educational institution to which the young children belong, having them evaluate the children's behavioral changes. Before participating in the program, young children were to have no difficulty in understanding and responding to the questions by receiving sufficient information about the questionnaire through their instructors regarding the activities. The pretest and posttest were done by the teachers that majored in early childhood education and have a daycare teacher's license, who have also been in charge of young children for at least 6 months.

Sonamu Nuri Forest Visitor Center for Little Children in Gangneung was established in 2014 with the area of 5ha. Major facilities include eco marsh, young children's forest shelter, forest playground and log foot bridge. For the forest experience programs, 10-15 young children formed a group to participate in the activities. Two forest guides for little children led the program for each group, assisted by daycare teachers who also sat in the class. The program mainly 
Table 1. Activities of the forest experience program for young children

\begin{tabular}{|c|c|c|}
\hline Activity domain & Activity subject & Activity contents \\
\hline \multirow{7}{*}{$\begin{array}{l}\text { Observation and exploration } \\
\text { of nature }\end{array}$} & How do trees survive winter? & - Observing trees \\
\hline & Breathing trees & - Studying vessel and sieve tubes \\
\hline & Wiggling larvae & - Studying the metamorphosis of larvae \\
\hline & Who lives underground? & - Observing underground creatures and understanding the importance \\
\hline & Friends at a pond & $\begin{array}{l}\text { - Children's story on the forest, 'Crawfish and Earthworm' and } \\
\text { observing animals around a pond }\end{array}$ \\
\hline & Come back, owl! & - Exploring and observing leaves, and having interest in wild animals \\
\hline & Scary wildfire & - Forest fire fighting trial and golden bell \\
\hline \multirow{2}{*}{ Crafting with natural objects } & \multirow{2}{*}{ Be a forest and play! } & - Crafting with wooden pieces \\
\hline & & - Drawing leaves \\
\hline Five-sense activities & Great forest feast in fall & - Exploring colors of fall and tasting tree fruits \\
\hline Games and physical activities & Free play in the forest & $\begin{array}{l}\text { - Building an Indian house, exhibition of Indian houses } \\
\text { - Peeking into habitats of boars } \\
\text { - Throwing pine cones } \\
\text { - Crocodile group game } \\
\text { - Moving logs, switching seats (log chairs) } \\
\text { - Sporting equipment activities in the forest } \\
\text { - Riding wooden horses }\end{array}$ \\
\hline
\end{tabular}

consisted of activities such as observation and exploration of nature, crafting using natural objects, five-sense activities, games and physical activities (Table 1).

\section{Measurement tools}

\section{Playfulness}

Play establishes the foundation for young children's holistic development, especially communication and social development, and is a key medium and means of education that helps understand young children's development and makes them interact. In other words, play has multiple educational functions and is an important medium of education and learning in early childhood education (Jeon and Lee, 2016).

Playfulness can be understood as the overt behavior in which the psychological traits of each of the young children is displayed as they play, as well as how much voluntarily they participate in the play depending on their internal motives about play and development status (Barnett, 1991).

To measure young children's playfulness, this study used the Children's Playfulness Scale (CPS) developed by Barnett (1990) and adapted and modified by Choi (2010). The CPS consists of 5 sub-factors such as physical spontaneity, social spontaneity, cognitive spontaneity, expression of joy, and sense of humor. In this study, the reliability of all items of playfulness (Cronbach's $\alpha$ ) turned out to be very high with .96, and all sub-factors also exceeded .80 , indicating that there was high internal consistency (Table 2). The items were rated on a 5-point Likert scale from 'Strongly disagree' (1 point) to 'Strongly agree' (5 points) based on the instructor's observation of young children's playfulness, with higher score indicating higher playfulness. 
Table 2. Composition and credibility of Children's Playfulness Scale

\begin{tabular}{lccc}
\hline \multicolumn{1}{c}{ Sub-factor } & Number of items & Cronbach's alpha & Measurement scale \\
\hline Physical spontaneity & 4 & .88 & \\
Social spontaneity & 5 & .93 & 5-point Likert scale \\
Cognitive spontaneity & 5 & .93 & (1:Strongly disagree $\sim 5:$ Strongly agree) \\
Expression of joy & 5 & .92 & \\
Sense of humor & 4 & .93 & .96 \\
\hline Total & 23 & &
\end{tabular}

\section{Emotional intelligence}

Emotional intelligence is the ability to understand one's own or other's feelings and emotions and adequately use them in thinking and actions, and is a sub-factor of social intelligence (Choi, 2010). Salovey \& Mayer (1990) that first used the concept of emotional intelligence defined it as the "ability to monitor one's own and other's feelings and emotions, to discriminate among them and to use this information to guide one's thinking and actions," and saw it as a category of social intelligence. Emotional intelligence is a key factor of young children's development, performing a crucial role in helping them perceive and control their emotional state, and understand and react to other's thinking and emotions so that they can maintain desirable human relations, thereby promoting their social development (Koh and Lee, 2008).

To measure young children's emotional intelligence, this study used the 'Young Children's Emotional Intelligence Scale' for the teacher's evaluation developed by Lee (1997), which consists of 4 sub-factors such as self-emotional recognition, self-emotional regulation, other's emotional recognition, and other's emotional regulation. In this study, the reliability of all items of emotional intelligence (Cronbach's $\alpha$ ) was high with .98 and all sub-factors also exceeded .90 , indicating that there was high internal consistency and enough confidence (Table 3). The items were rated on a 5-point Likert scale from 'Strongly disagree' (1 point) to 'Strongly agree' (5 points) by the instructors, with higher score indicating higher intelligence of young children.

\section{Analysis method}

Total 53 copies of effective samples about young children's general characteristics, playfulness and emotional intelligence were statistically analyzed using SPSS Statistics Ver. 21. In the process, this study conducted descriptive statistics to determine the general characteristics of young children, reliability testing of each sub-factor of playfulness and emotional intelligence (Cronbach's $\alpha$ ), and paired t-test to determine changes in young children's playfulness and emotional intelligence before and after participating in forest experience activities.

Table 3. Composition and credibility of Emotional Intelligence Scale

\begin{tabular}{|c|c|c|c|}
\hline Sub-factor & Number of items & Cronbach's alpha & Measurement scale \\
\hline Self-emotional recognition & 7 & .94 & \\
\hline Self-emotional regulation & 8 & .96 & \\
\hline Other's emotional recognition & 7 & .97 & $\begin{array}{c}\text { 5-point Likert scale } \\
\text { (1:Strongly disagree } \sim 5 \text { :Strongly agree) }\end{array}$ \\
\hline Other's emotional regulation & 9 & .93 & \\
\hline Total & 31 & .98 & \\
\hline
\end{tabular}




\section{Results and discussions}

\section{General characteristics of young children participating in forest experience activities}

The characteristics of respondents used in the final analysis are as follows (Table 4). Total 53 young children that participated in the forest experience activities ( 24 male, 29 female), where 4 children were 3 years old (7.5\%), 13 were 4 (24.5\%), and 36 were 5 (67.9\%), indicating that children aged 5 took up the highest ratio. Moreover, $66 \%$ of the participants turned out to have experience participating in a similar program before.

\section{Verification of research questions}

\section{Change in young children's playfulness through forest experience activities}

As shown in (Table 5), the mean of young children's playfulness increased from 3.45 to 4.05 after the forest experience

Table 4. Demographics of participants

\begin{tabular}{|c|c|c|c|}
\hline \multicolumn{2}{|c|}{ Division } & \multirow{2}{*}{$\frac{\text { Number of participants }}{24}$} & \multirow{2}{*}{$\frac{\text { Percent }(\%)}{45.3}$} \\
\hline & Male & & \\
\hline Gender & Female & 29 & 54.7 \\
\hline \multirow{3}{*}{ Age } & 3 years & 4 & 7.5 \\
\hline & 4 years & 13 & 24.5 \\
\hline & 5 years & 36 & 67.9 \\
\hline \multirow{2}{*}{ Experience of similar activity } & No & 18 & 34.0 \\
\hline & Yes & 35 & 66.0 \\
\hline Total & & 53 & 100.0 \\
\hline
\end{tabular}

Table 5. Result of the paired t-test: Young children's playfulness

\begin{tabular}{|c|c|c|c|c|c|}
\hline \multicolumn{2}{|c|}{ Variable } & \multirow{2}{*}{$\frac{\mathrm{M}}{3.45}$} & \multirow{2}{*}{$\begin{array}{l}\text { SD } \\
.356\end{array}$} & \multirow{3}{*}{$\begin{array}{c}\mathrm{t} \\
-6.271\end{array}$} & \multirow{3}{*}{$\begin{array}{c}p \\
.000^{*}\end{array}$} \\
\hline \multirow{2}{*}{$\begin{array}{l}\text { (Total) } \\
\text { Playfulness }\end{array}$} & Pre-test & & & & \\
\hline & Post-test & 4.05 & .571 & & \\
\hline \multirow{2}{*}{$\begin{array}{l}\text { (Factor 1) } \\
\text { Physical spontaneity }\end{array}$} & Pre-test & 3.70 & .479 & \multirow{2}{*}{-5.906} & \multirow{2}{*}{$.000^{*}$} \\
\hline & Post-test & 4.28 & .489 & & \\
\hline \multirow{2}{*}{$\begin{array}{l}\text { (Factor 2) } \\
\text { Social spontaneity }\end{array}$} & Pre-test & 3.46 & .431 & \multirow{2}{*}{-5.220} & \multirow{2}{*}{$.000^{*}$} \\
\hline & Post-test & 4.08 & .665 & & \\
\hline \multirow{2}{*}{$\begin{array}{l}\text { (Factor 3) } \\
\text { Cognitive spontaneity }\end{array}$} & Pre-test & 3.27 & .528 & \multirow{2}{*}{-3.304} & \multirow{2}{*}{$.002^{*}$} \\
\hline & Post-test & 3.72 & .697 & & \\
\hline \multirow{2}{*}{$\begin{array}{l}\text { (Factor 4) } \\
\text { Expression of joy }\end{array}$} & Pre-test & 3.45 & .529 & \multirow{2}{*}{-6.322} & \multirow{2}{*}{$.000^{*}$} \\
\hline & Post-test & 4.15 & .737 & & \\
\hline \multirow{2}{*}{$\begin{array}{l}\text { (Factor 5) } \\
\text { Sense of humor }\end{array}$} & Pre-test & 3.43 & .505 & \multirow{2}{*}{-5.605} & \multirow{2}{*}{$.000^{*}$} \\
\hline & Post-test & 4.08 & .820 & & \\
\hline
\end{tabular}

* Significant at $p<.01$ by paired t-test. 
activities, showing statistical significance $(\mathrm{t}=-6.271, p=.000)$. In other words, young children showed an increased playfulness, which was an individual's perception or attitude in leading a spontaneous behavior, in the process of playing during the activities.

By sub-factor of playfulness, it was found that all factors such as 'physical spontaneity', 'social spontaneity', 'cognitive spontaneity', 'expression of joy', and 'sense of humor' showed an increase after participation with statistical significance. 'Expression of joy ( $\mathrm{t}=-6.322, p=.000)$ ' and 'sense of humor ( $\mathrm{t}=-5.605, p=.000)$ ' showed a relatively great increase, whereas 'cognitive spontaneity ( $\mathrm{t}=-3.304, p=.002)$ ' showed the least improvement. This indicates that young children's ability to express emotions such as pleasure, achievement and joy improved through the activities, and they also showed humor such as conversations, stories and language that bring laughter and wit by interacting with their peers.

These results are in line with the argument of Kim (2010) and Han (2006) that forests enrich young children's play activities, and young children naturally interact with their peers in the process of using various natural objects in the forest as playthings. Therefore, forest experience activities have a positive effect on improving playfulness of young children.

\section{Change in young children's emotional intelligence through forest experience activities}

As a result of analyzing change in young children's emotional intelligence before and after participating in forest experience, it was found that the mean increased from 3.33 to 3.71 after participation, showing statistical significance $(\mathrm{t}=-4.309, p=.000)$. In other words, young children perceived and distinguished their emotions and others' during the activities, and showed improvement in the ability to guide their thoughts or actions using this information (Table 6).

By sub-factor of emotional intelligence, it was found that all factors such as 'self-emotional recognition', 'self-emotional regulation', 'other's emotional recognition', and'other's emotional regulation'showed an increase after participation with statistical significance, especially'other's emotional recognition $(\mathrm{t}=-6.334, p=.000)$ '. This indicates that young children well perceive the emotional response of peers or teachers during the activities, and show improvement in the ability to be empathic and react accordingly.

These results support Lee (2013) claiming that forest experience activities are effective in making young children control and express their emotions, consider and respect others, and obtain socialized behavior. Emotional intelligence is

Table 6. Result of the paired t-test: Young children's emotional intelligence

\begin{tabular}{|c|c|c|c|c|c|}
\hline \multicolumn{2}{|c|}{ Variable } & \multirow{2}{*}{$\frac{M}{3.33}$} & \multirow{2}{*}{$\begin{array}{l}\text { SD } \\
.362\end{array}$} & \multirow{3}{*}{$\begin{array}{c}\mathrm{t} \\
-4.309\end{array}$} & \multirow{3}{*}{$\begin{array}{c}p \\
.000^{*}\end{array}$} \\
\hline (Total) & Pre-test & & & & \\
\hline Emotional intelligence & Post-test & 3.71 & .608 & & \\
\hline \multirow{2}{*}{$\begin{array}{l}\text { (Factor 1) } \\
\text { Self-emotional recognition }\end{array}$} & Pre-test & 3.43 & .381 & \multirow{2}{*}{-5.606} & \multirow{2}{*}{$.000^{*}$} \\
\hline & Post-test & 4.01 & .664 & & \\
\hline \multirow{2}{*}{$\begin{array}{l}\text { (Factor 2) } \\
\text { Self-emotional regulation }\end{array}$} & Pre-test & 3.15 & .561 & \multirow{2}{*}{-5.089} & \multirow{2}{*}{$.000^{*}$} \\
\hline & Post-test & 3.75 & .800 & & \\
\hline \multirow{2}{*}{$\begin{array}{l}\text { (Factor 3) } \\
\text { Other's emotional recognition }\end{array}$} & Pre-test & 3.29 & .417 & \multirow{2}{*}{-6.334} & \multirow{2}{*}{$.000^{*}$} \\
\hline & Post-test & 3.97 & .742 & & \\
\hline \multirow{2}{*}{$\begin{array}{l}\text { (Factor 4) } \\
\text { Other's emotional regulation }\end{array}$} & Pre-test & 3.44 & .370 & \multirow{2}{*}{-6.311} & \multirow{2}{*}{$.000^{*}$} \\
\hline & Post-test & 4.04 & .607 & & \\
\hline
\end{tabular}

* Significant at $p<.01$ by paired t-test. 
more important in early childhood because development of emotional intelligence in early childhood has a significant effect on emotional development after that. Thus, it is very important to create an environment for young children to have abundant emotional experience (Choi, 2010). Thus, unstructured and spontaneous activities in the forest provide young children with opportunities to develop various senses, while also having significant effects on their recognition and expression of emotions and improvement in regulating ability by actively interacting with their peers.

\section{Conclusion}

This study analyzes the effects of forest experience activities on young children's playfulness and emotional intelligence targeting 53 young children that participated in forest experience activities at a forest visitor center for little children organized and run by Korea Forest Service, and the results are as follows.

First, as a result of analyzing the effects of forest experience activities on young children's playfulness, it was found that their playfulness increased with statistical significance after participating in the activities. All sub-factors of playfulness such as 'physical spontaneity', 'social spontaneity', 'cognitive spontaneity', 'expression of joy', and'sense of humor' increased with statistical significances. This indicates that during the activities, young children show improvement in their ability to express emotions and sense of humor, cooperate with the peers or perform self-initiated role using rules or methods creatively, and have positive effect on improving their motor skills through physical activities. These results are consistent with Lee and Kim (2015) that determines the effects of forest experience activities on young children's emotional intelligence.

Second, as a result of analyzing the effects of forest experience activities on young children's emotional intelligence, it was found that forest experience activities had positive effects on improving young children's emotional intelligence. All sub-factors of emotional intelligence such as 'self-emotional recognition', 'self-emotional regulation', 'other's emotional recognition', and 'other's emotional regulation' increased with statistical significance. This supports Lee (2011) claiming that forest experience has a positive effect on increasing emotional intelligence of young children, and Häfner (2003) claiming that play activities in the forest enrich children's emotions.

These results show that forest experience activities will help young children achieve a healthy development in terms of physical, emotional, social and cognitive aspects. This may have originated from how young children recognize and commune with various living things in the natural space of a forest are self-initiative in using them for play, and perceive and build desirable relations between nature and people or among people by interacting with others. In particular, play performs a crucial educational function in young children's development, and their playfulness is closely related to improving social ability that is one of the living abilities (Lee, 2004; Jeon and Lee, 2016). Thus, forest experience activities are expected to have positive effects on young children in obtaining the social skills to get along and smoothly interact with others.

This study is limited in terms of generalizing the results as it only examined 53 young children as the subjects. Continuous observations and discussions on the variables are needed as the results are obtained through just one posttest. Therefore, follow-up research must verify the effects of forest experience activities depending on the durability of activities or socio-demographic variables, and conduct in-depth investigation of the interaction between environmental elements of forests and young children. Furthermore, it is also necessary to study the awareness and demand for forest experience activities of young children in the situation where there are more and more researches and awareness about the positive effects of the forest experience activities on young children's development. 


\section{References}

An, M.S. 2006. The effects of nature-experience activities through forests and streams on young children's ecological attitudes. Master's thesis, Incheon University, Incheon, Korea.

Baek, G.H. 2014. The influence of ecology experience activity on nature-friendly attitude and life respect concept of preschoolers. Master's thesis, Kyungnam University, Changwon, Korea.

Barnett, L.A. 1990. Development benefits of play for children. J. Leis. Res. 22(2):138-153. DOI:10.1080/00222216.1990.11969821

Barnett, L.A. 1991. The playful child: Measurement of a disposition to play. Play Cult. 4(1): 51-74.

Cho, H.S. 2005. The development and evaluation of a nature friendly program for young children. Korean J. Early Child. Educ. 25(5):343-366.

Choi, E.H. 2010. A study on leadership, playfulness and emotional intelligence of young children. Master's thesis, Chung-Ang University, Seoul, Korea.

Choi, S.K. 2013. The development and effects of young children's play program in the forest. Master's thesis, Yeungnam University, Gyeongbuk, Korea.

Häfner, P. 2003. Wie schulfähig macht der Waldkindergarten? Kindergarten heute 4:32-35. Retrieved from http://www. waldkindergarten-alzenau.de/public/konzeption/wie-schulfaehig-macht-der-waldkindergarten.html

Han, J.S. 2006. A study on presenting art-expression through ecological play of children in preschool: based on my teaching case. Master's thesis, Hong-Ik University, Seoul, Korea.

Hong, Y.S. 2015. The effect of forest-kindergarten's forests activities on the self-leadership of infant. Master's thesis, Hankuk University of Foreign Studies, Seoul, Korea.

Jeon, I.O. and K.O. Lee. 2016. Introduction to Early Childhood Education. Seoul. Korea: Korea National Open University Press.

Jin, B.H. 2013. The effect on young children's happiness and sociality from the nature-friendly experience of forest. Master's thesis, Gwangju University, Gwangju, Korea.

Kang, S.Y. 2013. Physical activities in the early childhood at the forest kindergarten. J. Korean Soc. Early Child. Phys. Educ. 14(2):45-55.

Kim, E.S. 2010. A study on the first forest-kindergarten education in Korea. Doctoral dissertation, Incheon University, Incheon, Korea.

Kim, H.H. 2014. The effects of forest experience activity upon children's self-esteem. Master's thesis, Nambu University, Gwangju, Korea.

Kim, K.H. 2016. The effects of forest activities on young children's motor skills. Master's thesis, Incheon University, Incheon, Korea.

Kim, M.O. 2013. The effects of MeFOT-based forest activities and free forest activities on the creativity and scientific inquiry process skills of preschoolers. Master's thesis, Dong-A University, Busan, Korea.

Kim, S.M. [Sung Mi]. 2008. An effect of the nature-friendly experience activity on sociality development of young children. Master's thesis, Hankuk University of Foreign Studies, Seoul, Korea.

Kim, S.M. [Si Mok]. 2016. Effects of activity in a forest on children's personality trait and positive attitude. Master's thesis, Dongguk University, Seoul, Korea.

Koh, I.S. and J.S. Lee. 2008. Effect of preschools' problem behavior by social competence and emotive intelligence. J. Korean Assoc. Child Psychother. 3(1):93-111.

Lee, B.N. 1997. Relationship between kindergartners' emotional intelligence and their parents' psychological life position. Doctoral dissertation, Chung-Ang University, Seoul, Korea.

Lee, D.R. 2013. Influence of forest activity on children's emotional intelligence and awareness. Master's thesis, Dongguk University, Seoul, Korea. 
Lee, I.S. 2011. Experiences of young children participating in nature-experiencing activities in the wood. Master's thesis, Korea National University of Education, Seoul, Korea.

Lee, J.G. 2004. The relationships between mothers' and young children's playfulness and young children's competence. Master's thesis, Kyounghee University, Seoul, Korea.

Lee, M.H. and E.S. Kim. 2015. The effect of storytelling activities in the forest on the children's emotional intelligence. J. Korean Soc. Holist. Educ. 19(4):141-158.

Oh, N.R. 2017. Influence of ecological experiences in the forest on infant's nature-friendly attitude and awareness by ecological experiences in the forest. Master's thesis, Kyunghee University, Seoul, Korea.

Oh, S.H. 2014. The influence of forest experience activities on the children's emotional intelligence and the changing process of perception \& attitudes towards nature. Master's thesis, Dongguk University, Seoul, Korea.

Park, Y. 2015. The impact of child forest activities on stress and aggression: with measures of children educational services. Master's thesis, Hansei University, Gunpo, Korea.

Richard, L. 2005. Last Child in the Woods: Saving Our Children From Nature-Deficit Disorder (1st ed). New York, NY: Workman Publishing Company.

Salovey, P. and J.D. Mayer. 1990. Emotional intelligence. Imagin. Cogn. Pers. 9(3):185-211. DOI:10.2190/DUGG-P24E52WK-6CDG

Seo, Y.M. 2007. The effects of mathematical inquiry activity based on forest experience on the children`s mathematical problem solving ability and attitude toward mathematics. Master's thesis, Chungang University, Seoul, Korea.

Son, M.S. 2016. The effects of forest activities on preschoolers' scientific exploration skills and scientific mind. Master's thesis, Kangwon National University, Gangwon-do, Korea.

Song, Y.I. 2017. The effects of storytelling-applied forest activities on the language expression and pro-environmental attitudes in young children. Master's thesis, Kongju National University, Chungcheongnam-do, Korea.

Yoo, K.J. 2013. The effect of nature kindergarten activities on children's prosocial behavior and emotional expression. Master's thesis, Seoul National University of Education, Seoul, Korea.

Yoo, S.H. 2015. The effects of small group poetry writing activities through forest experiences on young children's language expression and emotional intelligence. Master's thesis, Gyeongin National University of Education, Gyeonggi-do, Korea.

Yun, G.A. 2013. The effects of forest play activity upon childrens daily stress reduction. Master's thesis, Seoul National University of Education, Seoul, Korea. 